\title{
RESPONSABILIDAD SOCIAL UNIVERSITARIA. SU TRASCENDENCIA EN EL CONTEXTO REGIONAL
}

HÉCTOR OJEDA CONCURSO $60^{\circ}$ ANIVERSARIO - NO DOCENTE FACULTAD DE CIENCIAS ECONÓMICAS - UNNE 


\section{RESUMEN}

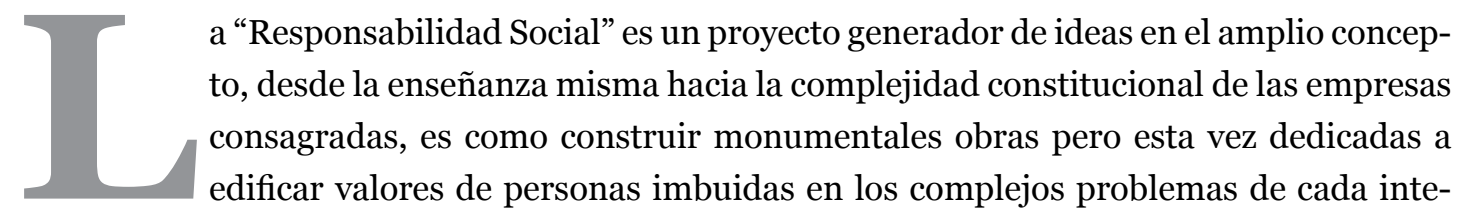
grante, partícipes de ese gran cuerpo que, como partes interesadas que somos, reclamamos su intervención en los procesos organizativos. Por eso es la necesidad de responder a la sociedad, esta Facultad de Ciencias Económicas templa a los estudiantes en la ética, claramente propuesta en su misión y la promoción diaria que se va exhibiendo, dirigida hacia la sociedad productiva de la región como desde sus orígenes fuera propuesta para la solución de la demanda social. Y finalizaré exponiendo mis conclusiones al respecto.

\section{INTRODUCCIÓN A LA RESPONSABILIDAD SOCIAL}

La propuesta de la idea de Responsabilidad Social surge del sector privado. Tomándolo desde un enfoque humanitario de la inversión social y entendiéndose como nuevo paradigma "la Responsabilidad Social en la Universidad" implica intentar superar una "proyección social y extensión universitaria”, haciendo que esta propuesta no sea solamente una bienaventuranza, sino sea más bien la intención reflexiva de enfocarse en la función primordial que es la enseñanza y la producción de conocimientos para estudiantes, centrados en la realidad socioeconómica que por hoy se nos presentan caratuladas con la "Responsabilidad Social”, cuya trascendencia propone a la universidad crear una conciencia a largo plazo, futura inversión hacia una organización socioeconómica más humanizada.

\section{LA FACULTAD DE CIENCIAS ECONÓMICAS A TRAVÉS DE LA HISTORIA Y EL PRESENTE}

En la introducción destaco en esta breve reseña a la UNNE como parte integrante de la gran red de Universidades Argentinas y a la Facultad de Ciencias Económicas como entidad nacida, lo interpretaría, como necesidad de las economías de esta Región Nordeste Argentino.

Desde los tiempos reformistas de los años 1918, en la que la política y la sociedad Argentina, en propuesta de cambios dirigidas por los estudiantes cordobeses, comenzando por esto un debate, por el cual se fueron gestando a través de los años, esos cambios que hasta hoy se van planteando en la política y en la organización de las instituciones, que se encuentran conmocionadas por las innovaciones tecnológicas que se van dando en la vida socioeconómica de esta región.

En los años de 1950 se viene generando por medio de las Universidades Nacionales del Litoral y de Tucumán y dependientes a ellas, por ejemplo la Facultad de Agricultura, Ganadería e Industrias afines con sus sedes en la ciudad de Corrientes y como declara en el institucional de la página web la UNNE, surge el Instituto Nacional de Profesorado, autorizado por el 
Rectorado de la Universidad Nacional del Litoral el 6 de junio de 1951. Ese mismo año, meses antes, el 30 de abril de 1951 según Resolución $\mathrm{N}^{\circ} 262$ dictada por la Universidad Nacional del Litoral, autorizaba a la Facultad de Ciencias Económicas, Comerciales y Políticas, a crear en la ciudad de Resistencia una división de primer año de la carrera de Contador Público y Perito Partidor. Cuya aparición responde al pedido del Gobernador del Territorio Nacional del Chaco, por inquietud del entonces Director de la Escuela Nacional de Comercio de Resistencia, tal como lo menciona en la síntesis de la citada página. Y luego con la provincialización de los territorios nacionales, la necesidad de la voluntad de crear un centro universitario en la región, por el aumento de la matrícula secundaria y la creciente demanda de la creación de numerosos establecimientos de ese nivel, entonces se presentó la necesidad de más profesores y el problema de la emigración de los jóvenes hacia otros centros en busca de un futuro mejor.

Todas esas problemáticas evidenciadas, sumada la de otras inquietudes, surge como respuesta la UNIVERSIDAD NACIONAL DEL NORDESTE, el 14 de diciembre de 1956 por Decreto Ley $\mathrm{N}^{0} 22.229$.

Después de esta conmemoración de los orígenes de nuestra UNNE, caigo nuevamente en la teoría conceptual de que, como figura principal y destacable, la función docente en la investigación y en la extensión, brindando su saber y arte de planificar y administrar los recursos del conocimiento, tarea nada sencilla.

Puedo mencionar a la Facultad de Ciencias Económicas, reconocida como un centro o lo llamaría área de la enseñanza superior de las Ciencias Económicas, dedicadas a la investigación y a la extensión universitaria, inserta en la órbita de la UNNE y además considero a la mencionada Facultad como un ápice creado para un mejor manejo de los estudiantes dedicados a las Ciencias de la Economía y los que son tenidos en cuenta, en un futuro no muy lejano, como recursos humanos.

A su vez, estos estudiantes pueden ser administrados por el Área de alumnado, las Direcciones de Carreras, las Áreas de Investigación y los Postgrados, todos ellos de una u otra forma aportan a la sociedad.

Y a todas estas subdivisiones dispuestas para los estudiantes de grado y postgrado, lo llamaría como entes vinculantes progresistas a los centros de extensión, encargados de organizar cursos de capacitación y/o actualización de profesionales y alumnos, recepción de trabajos encomendados por terceros, realización de convenios con otras organizaciones o universidades, etc. Toda esta acción origina la inserción de los futuros profesionales pero ya inculcados en cuestiones pertinentes a la sociedad-económica de la región.

Cabe señalar a modo de referencia, sobre los orígenes de esta idea son reflejados en un discurso del Dr. Risieri Frondizi en su carácter de Director Organizador de la Enseñanza Universitaria, el $1^{0}$ de abril de 1957, a la entrega de los Institutos Universitarios del Chaco a las autoridades designadas por el Gobierno Nacional, dijo lo siguiente: (...) "La Universidad del Nordeste debe ser Regional, pero no provinciana. Hay que atender a lo universal y a lo particular al mismo tiempo. $\mathrm{O}$, mejor dicho, enfrentar lo particular con una actitud universalista”(...), 
creo que estas palabras definen el objetivo y la finalidad que tiene la constitución de la Universidad misma, plasmadas a fuego en el ideal de cada Institución perteneciente a la UNNE.

Esta facultad está constituida por cinco Secretarías dedicadas al flujo estudiantil y las mismas son: Secretaría Académica, Secretaría de Asuntos Estudiantiles, Secretaría de Extensión, Secretaría de Postgrado y la Secretaría de Investigación, Innovación y Desarrollo.

Destaco a la Secretaría de Extensión su labor extraordinaria en abarcar los temas de requerimiento sociales, sumada la colaboración y esto lo mencionaría a modo personal, la importancia que va adquiriendo la Secretaría de Postgrado, dedicada a revitalizar las carreras y cursos de postgrado dirigidas todas ellas a enaltecer el conocimiento y perfeccionamiento de la planta docente que pertenezcan o no a esta Facultad, aportando con nuevas especialidades a los profesionales de la región del nordeste argentino. Y la Secretaría de Investigación, Innovación y Desarrollo encargada de proponer nuevas formas de plantear la educación en el sistema universitario, como ser proponiendo proyectos o recibiéndolos, becas de investigación (pregrado, iniciación, perfeccionamiento, especializaciones, etc.). En definitiva estas secretarías reciben los temas o propuestas y proponen proyectos en busca de los resultados, claro está, proveniente de los reclamos de la misma sociedad, demostrando cada día la Responsabilidad Social al establecer un vínculo equidistante con la realidad de nuestros tiempos, en los cuales vamos transitando con los problemas e inconvenientes presentes.

Y esa propuesta se van dando, ejemplo de ello se lo puede leer en las páginas virtuales denominadas "Semana Profesional” y el "Diario Norte" artículos del 5 de abril de 2011, (de que pude recabar) del cual se refieren al "Ciclo de charlas enmarcadas en los 60 años de la Facultad de Ciencias Económicas de la UNNE”, esta institución es participante además del Programa Nacional de Formación en Ética para el Desarrollo de una nueva generación de jóvenes conscientes de la necesidad del desarrollo local con ética y compromiso social.

En esta oportunidad el Profesor Cristián Piris se refirió ante un escenario colmado de estudiantes avanzados, docentes y profesionales en el Salón de Usos Múltiples de la Facultad de Ciencias Económicas, sobre "La Responsabilidad Social Universitaria" dijo que "es un término amplio, aún en consolidación, pero que la UNNE ha decidido adoptarla como guía de su gestión como lo han hecho las principales instituciones de Educación Superior", estas consideraciones se pueden distinguir la firme decisión de consagrar la idea de adoptar los principios responsables hacia un cambio de mentalidad.

También explicó “que mientras el término responsabilidad en el ámbito jurídico está ligado al incumplimiento, en el ámbito social y de la universidad refiere a compromiso y se constituye en uno de sus fines”. En estas expresiones imprime el afán que tiene la Universidad Nacional del Nordeste en su política de integrar como un "compromiso" y en un "fin" la iniciativa de incluirse al ámbito Social Universitario.

$\mathrm{Y}$ dando matiz a todo estos conceptos preliminares y creo que como último mensaje o ente receptor de una nueva conciencia, define a "la Responsabilidad Social Universitaria," recalcando - "que no es filantropía ni extensión universitaria, y que se rige por la ética de las 
acciones, no de las intenciones. No es puramente moral ni de buenas intenciones, sino que es una acción porque es el resultado o impacto bueno de lo que hacemos". Con estas consideraciones, además de hacer referencia y a su vez la distinción del papel de la Universidad, diferenciándola de la Responsabilidad Social de las Empresas, comprende e interpreta a la Responsabilidad Social Universitaria como una acción de impacto para movilizar las conciencias en el ámbito Universitario hacia la Sociedad.

Con estas últimas consideraciones por la que "La Responsabilidad Social que buscamos integra las dimensiones de formación académica y docencia, la producción y difusión de conocimiento, y la participación y responsabilidad hacia el medio" finalizó. Por ello explica las dimensiones de este gran cambio generacional de alumnos y situacional de integración completa de la Universidad al contexto social y la búsqueda de un concepto actualizado de una institución dinámica y que pueda responder a las exigencias propuestas por el mundo actual.

Este "Programa Nacional de Formación en Ética para el Desarrollo por un acuerdo con la Universidad de Buenos Aires se dicta en la UNNE en el marco del 60 aniversario de la Facultad de Ciencias Económicas."

Considerando lo argumentado en el artículo de la página web (Aventus Nocias) "UNNE: analizan la responsabilidad social como rol del empresariado" - 28/03/2011 - , prosiguiendo con las charlas programadas en la Facultad de Ciencias Económicas referente a la Responsabilidad Social, ante un numeroso grupo de estudiantes y profesionales, los profesores contadora Rossana Greco y la abogada y docente Sandra Umansky, investigadoras de la UNNE en el análisis de la responsabilidad social empresaria con relación a los consumidores, uno de los eslabones del sistema económico.

La interpretación precisa y concisa de la profesora Greco sobre "La idea de la responsabilidad social empresaria" - dice - "no está enfocada solo a las obligaciones de las empresas, sino además las posibilidades de contribuir al bienestar social sin afectar sus fines económicos”.

Además se refiere a la responsabilidad empresaria, su relevancia actual y su importancia dentro del Programa Nacional de Formación en Ética para el Desarrollo y la necesidad de implementarlo en todo el país, como se lo está efectuando en la UNNE.

Mantuvo la idea de la responsabilidad empresaria como medio de gestión en las empresas, robusteciendo y equilibrando las relaciones sociales y económicas para lograr beneficios a los grupos interesados como lo son los clientes, estado, proveedores y la sociedad en general. Además la profesora Greco se refirió al programa de formación como propuesta a la formación de jóvenes inspirados en estas nuevas ideas y espera se conviertan como agente multiplicadores en sus respectivos lugares de trabajo y ámbito social.

Como principales objetivos se distinguen la inserción en la labor docente de egresados como auxiliares de cátedra y la promoción de los jóvenes en el desarrollo e implementación de proyectos sociales concretos.

Cabe destacar que la coordinadora del proyecto contadora Noelia Franchini, se refirió sobre los trabajos con alumnos próximos a recibirse, puedan ingresar a la temática y desarrollar 
vocación en la docencia e investigación, disponiéndose a establecer una conciencia ética en su ejercicio profesional, y continuó diciendo que "La idea es prepararlos para ser profesionales y docentes comprometidos con la cuestión” resaltó. Y señalo que los jóvenes puedan dedicarse a realizar trabajos de investigación y extensión enmarcados en un proyecto llamado "Ideas para la Región” con el propósito de fortalecer el compromiso social y empresarial en el desarrollo de esta Región Nordeste.

\section{3. ¿QUÉ ES LA RESPONSABILIDAD SOCIAL EMPRESARIAL?}

Antes de ir a la propuesta del tema de la Responsabilidad Social Universitaria que propone la UNNE, analizaré en breve el concepto o los conceptos de Responsabilidad Social Empresarial, para que nos determine el enfoque que busca en una organización moderna.

Se podría iniciar diciendo que la Responsabilidad Social Empresarial va más allá de toda magnanimidad. "No quiere decir filantropía pura" tal como lo dice el texto François Vallaeys, es decir, que no significa donación alguna y no es pertinente a la actividad de la empresa.

Tampoco dice que es "filantropía interesada", es decir, donación caritativa de productos de la empresa para promocionarlo con la intención de abrir nuevos mercados.

Por eso la Responsabilidad Social Empresarial "es un conjunto de prácticas de la organización que forma parte de su estrategia corporativa" y el fin determina su "estrategia”, es de impedir perjuicios y al contrario causar beneficios para todas las partes intervinientes pertenezca o no a la empresa, como ser los clientes, empleados, accionistas, comunidad, entorno, etc., en definitiva se busca el beneficio de la organización y del entorno social.

El libro Verde de la Unión Europea define el concepto "por el cual las empresas deciden contribuir voluntariamente a mejorar la sociedad y a preservar el medio ambiente. A través suyo, las empresas se concientizan del impacto de su acción sobre todos y expresan su compromiso de contribuir al desarrollo económico, a la vez que a la mejora de la calidad de vida de los trabajadores y sus familias, de la comunidad local donde actúan y de la sociedad en su conjunto". Y todos estos impactos que las empresas dan mejoramiento en la calidad de vida de sus trabajadores, se brinda al medio social y los cuidados tecnológicos se ocupan de proteger el medio ambiente.

Esta definición de la Responsabilidad Social Empresarial se la comprende "cómo la acción conjunta de toda la empresa concienciada (trabajadores, directivos y dueños) del papel que tiene ésta como unidad de negocio que crea valor y que pervive en un espacio del que se lucra. Concientización en el plano social (de ayuda a los más desfavorecidos y de respeto a los consumidores), ambiental (de sostenibilidad y responsabilidad con el medio ambiente) y económico (de prácticas leales, transparentes en el manejo de sus finanzas y de inversiones socialmente responsables). Es decir, la Empresa Buena”. Estos conceptos definen a la Responsabilidad Social Empresarial como entidades partícipes, comprometidas, responsables de crear una conciencia transparente y ambientalista, dotados del poder económico y ahora enriquecida aún más por el valor que le brindan a los derechos de sus trabajadores, dentro y fuera del ámbito laboral. 


\section{4. ¿QUÉ ES LA RESPONSABILIDAD SOCIAL UNIVERSITARIA?}

En este mundo comprendido por organizaciones, las que demandan ética en la práctica administrativa denominándolas actualmente como "Responsabilidad Social". En estos sistemas deben estar gobernados por una cierta libertad de acción e iniciativa, caracterizándolos en un mundo democrático y de libre mercado, las empresas no pueden pensar solo en sus intereses corporativos o marco legal que las protege, abandonando a su suerte la implicancia de sus decisiones adrede sin pensar en las consecuencias, el impacto general que ocasionaría esas acciones en el entorno social y ambiental. La ética responde con la Responsabilidad en los efectos (cercanos como lejanos) que puedan originar cambios no deseable en el mundo, por eso es preciso preocuparnos por el presente hacia el futuro, intentar ser partícipes en arreglar u organizar a la sociedad para su "prosperidad” y "posteridad”, según lo manifiesta nuestro preámbulo.

"La Responsabilidad Social es una exigencia ética” - según lo leí - y también lo completaría que una estrategia racional, motivadora al desarrollo de la inteligencia organizacional, es además una medida civilizadora en el ámbito laboral destinada hacia el mundo, para el mundo y con el mundo, y como último me parece que es intermediaria de responsabilidades conscientes y responsables.

Con las semejanzas de una empresa, la Universidad debió afrontar el cambio desde una mirada filantrópica al principio, resistiéndola como un gasto y no como una inversión social, en el nuevo paradigma de la Responsabilidad Social, la Universidad trata de resaltar su "proyección social y extensión universitaria" como complementos de su función central que es la formación estudiantil y la producción de conocimientos, como verdaderos requerimientos de la Responsabilidad Social Universitaria.

También este cambio de visión ha servido para ampliar el panorama de la reforma y encontrar, mediante este proceso que se está gestando, los malos conocimientos y epistemologías que las universidades se encargan de producir y a su vez trasmitir esa conciencia negativa y no colaborativa con el cambio que se propone. Por eso me parece necesaria una constante evaluación de los procedimientos administrativos y académicos, para diagnosticar y reformular en los aspectos que sean necesarios. Porque como ya dije, la Responsabilidad Social Universitaria en la UNNE debe ser una exigencia para todos, desde una visión holística, promover la educación desde las instituciones con proyectos de promoción social, encausados en los principios éticos y en el constante progreso en la producción y la transmisión de conocimientos y la formación de profesionales integrados a su comunidad, como profesionales responsables.

Según François Vallaeys, texto en el cual me estoy inspirando para realizar este análisis, enfocándose en cuatro líneas de acción institucional para orientar estratégicamente a la Responsabilidad Social Universitaria, siendo la:

- Gestión interna de la Universidad (meta orientadora hacia la transformación de la Universidad en una pequeña comunidad democrática). La Universidad debe ser ejemplo ante la ciudadanía.

- La docencia (la meta es de capacitar a los docentes en el enfoque de la Responsabilidad 
Social Universitaria y promover en las especialidades el Aprendizaje Basado en Proyectos de carácter social). La Universidad debe preparar a sus docentes hacia el proyecto de la Responsabilidad Social Universitaria.

- La investigación (la meta es de promover la investigación para el desarrollo, bajo todas las forma posibles). La Universidad debe promover la investigación para concertar estrategias que sirvan para extender el campo educativo superior hacia todos los lugares de la región.

- La proyección social (la meta es de trabajar en interfaz con los departamentos de investigación y los docentes de las diversas facultades para implementar y administrar proyectos de desarrollo). La Universidad tiene que implementar y administrar los proyectos de desarrollo, más la aplicación de la investigación y los recursos didácticos.

\section{CONCLUSIÓN}

Finalmente entiendo que la Universidad sin ser una empresa, hay que considerarla que funciona dentro de una sociedad, la que genera impactos a las personas tanto las que trabajan en ella, como ser los no docentes, docentes, estudiantes, etc. y sobre el entorno social, fuera de los límites del campus universitario.

La "Responsabilidad Social" es la respuesta a las necesidades éticas, signadas por un saber inteligente que produce impactos positivos, a partir de una visión integral de la organización, gestando una sociedad con responsabilidades. Cuidando a la misma Universidad de que esos impactos surgidas de ella misma, no ocasionen daños al medio ambiente, al medio social y los recursos humanos, intentando que los daños sean lo menos posibles, maximizando que los impactos sean positivos, a favor de la sociedad, para la sociedad y con la sociedad básicamente.

Puedo distinguir dos principios o propósitos de la Universidad y estas son:

- La formación humana y profesional (propósito académico)

- La construcción de nuevos conocimientos (propósito de investigación)

$\mathrm{Y}$ estos dos fines se entrelazan fuertemente con la investigación de sus profesores que constituyen a la Universidad, proveyéndoles contenidos académicos que los transfieren a los estudiantes para su perfeccionamiento en el ámbito profesional.

Completando la conclusión tomando las palabras del Dr. Piris en los artículos periodísticos mencionados con anterioridad los que en definitiva dan el concepto claro y preciso de la "Responsabilidad Social Universitaria, que no es filantropía ni extensión universitaria, y que se rige por la ética de las acciones, no de las intenciones. No es puramente moral ni de buenas intenciones, sino que es una acción porque es el resultado o impacto bueno de lo que hacemos”. Con estas consideraciones hace referencia y a su vez la distinción del papel de la Universidad, diferenciándola de la Responsabilidad Social de las Empresas, sabiéndose que la intencionalidad es impactar en un cambio de conciencia dirigida a la formación estudiantil e impartir conocimiento de la realidad social de la región para la producción de conocimientos y elaboración de proyectos locales. 
La necesidad de comprender a la "Responsabilidad Social Universitaria" como un nexo ente las Facultades e Institutos, para encarar el estudio del entorno Social en búsqueda de respuestas, para entender a la sociedad a la que nos brindamos, para darles alternativas ante la problemática y el entorno biótico para su conservación y cuidado.

\section{CITAS BIBLIOGRÁFICAS}

Semana Profesional - Pag. Web -

http://www.semanaprofesional.com/?nota $=27282$

Diario Norte - Pág. Web -

http://www.diarionorte.com/noticia.php?numero=63284

¿Qué es la Responsabilidad Social Universitaria? - Por François Vallaeys Palestra - Pág. Web http://www.url.edu.gt/PortalURL/Archivos/o9/Archivos/Responsabilidad_ Social_Universitaria.pdf

\section{REFERENCIAS BIBLIOGRAFICAS}

Historia de las Universidades Argentinas - de Pablo Buchbinder - Ed. Sudamericana -2005 .

Apuntes de la cátedra en su mayoría, los que están basados en la siguiente bibliografía: Material preparado por Lionel A. González Gervasoni, extraído del Módulo 4 Tema 5. La Gestión Académica. Gestión de Calidad Universitaria. Evaluación Institucional de Programas. (Organización y Administración de las Instituciones Universitarias - de la Carrera de Tecnicatura en Administración y Gestión de Instituciones Universitarias).

Máster Internacional en Gestión Universitaria. $1^{0}$ Edición Argentina. 2009-2010. Universidad de Alcalá de Henares. España.

Hitt Michael A., Black J. Stewart, Porter, Lyman W. (2006) Administración. 9a edición. México. Editorial Person Educación de México.

Robbins Stephen P. (1994) Comportamiento Organizacional. Conceptos, Controversias y Aplicaciones. Editorial Prentice Hall Hispanoamericana S.A. $6^{0}$ Edición. México. 


\section{CURRÍCULUM VITAE}

HÉCTOR LUIS OJEDA

Personal No Docente desde 1987, promovido a planta permanente en 1993. Desempeña tareas de administración en Mesa de Entradas, Salidas y Archivo de la Facultad de Ciencias Económicas de la UNNE.

Técnico en Administración y Gestión de las Instituciones Universitarias, egresado de la UNNE, en 2012.

Ha asistido y aprobado numerosos cursos de formación y perfeccionamiento.

hectorojeda63@hotmail.com 